\title{
Front Matter: Volume 6829
}

, "Front Matter: Volume 6829," Proc. SPIE 6829, Advanced Materials and Devices for Sensing and Imaging III, 682901 (29 January 2008); doi: 10.1117/12.784281

SPIE. Event: Photonics Asia 2007, 2007, Beijing, China 


\title{
PROCEEDINGS OF SPIE
}

\section{Advanced Materials and Devices for Sensing and Imaging III}

\author{
Anbo Wang \\ Yimo Zhang \\ Yukihiro Ishii \\ Editors
}

12-14 November 2007

Beijing, China

Sponsored by

SPIE - COS—Chinese Optical Society

Cooperating Organizations

OSJ-Optical Society of Japan - OSK-Optical Society of Korea - Australian Optical Society • Optical Society of Singapore $\bullet$ Beijing Institute of Technology (China) • Beijing University of Posts and Telecommunications (China) • Peking University (China) • Tsinghua University (China) • Zhejiang University (China) • Changchun University of Science and Technology (China) • University of Shanghai for Science and Technology (China) • Shanghai Jiao Tong University (China) • Tianjin University (China) Nankai University (China) • Shanghai Institute of Optics and Fine Mechanics (China) • Changchun Institute of Optics and Fine Mechanics (China) • Institute of Semiconductor s (China) • Institute of Optics and Electronics (China) - Shanghai Institute of Technical Physics (China) • China Instrument and Control Society • China Solid State Lighting Research and Industry Alliance • Optoelectronics Technology Committee, COS (China)

Supporting Organizations

CAST_China Association for Science and Technology (China) - NNSF-National Nature Science Foundation (China) • The Ministry of Science and Technology (China)

Published by

SPIE

Volume 6829 
The papers included in this volume were part of the technical conference cited on the cover and title page. Papers were selected and subject to review by the editors and conference program committee. Some conference presentations may not be available for publication. The papers published in these proceedings reflect the work and thoughts of the authors and are published herein as submitted. The publisher is not responsible for the validity of the information or for any outcomes resulting from reliance thereon.

Please use the following format to cite material from this book:

Author(s), "Title of Paper," in Advanced Materials and Devices for Sensing and Imaging III, edited by Anbo Wang, Yimo Zhang, Yukihiro Ishii, Proceedings of SPIE Vol. 6829 (SPIE, Bellingham, WA, 2007) Article CID Number.

ISSN 0277-786X

ISBN 9780819470041

Published by

SPIE

P.O. Box 10, Bellingham, Washington $98227-0010$ USA

Telephone +1 3606763290 (Pacific Time) · Fax +1 3606471445

SPIE.org

Copyright (c) 2008, Society of Photo-Optical Instrumentation Engineers

Copying of material in this book for internal or personal use, or for the internal or personal use of specific clients, beyond the fair use provisions granted by the U.S. Copyright Law is authorized by SPIE subject to payment of copying fees. The Transactional Reporting Service base fee for this volume is $\$ 18.00$ per article (or portion thereof), which should be paid directly to the Copyright Clearance Center (CCC), 222 Rosewood Drive, Danvers, MA 01923. Payment may also be made electronically through CCC Online at copyright.com. Other copying for republication, resale, advertising or promotion, or any form of systematic or multiple reproduction of any material in this book is prohibited except with permission in writing from the publisher. The CCC fee code is 0277-786X/08/\$18.00.

Printed in the United States of America.

Publication of record for individual papers is online in the SPIE Digital Library.

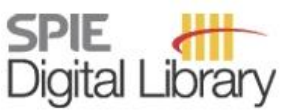

SPIEDigitalLibrary.org

Paper Numbering: Proceedings of SPIE follow an e-First publication model, with papers published first online and then in print and on CD-ROM. Papers are published as they are submitted and meet publication criteria. A unique, consistent, permanent citation identifier (CID) number is assigned to each article at the time of the first publication. Utilization of CIDs allows articles to be fully citable as soon they are published online, and connects the same identifier to all online, print, and electronic versions of the publication. SPIE uses a six-digit CID article numbering system in which:

- The first four digits correspond to the SPIE volume number.

- The last two digits indicate publication order within the volume using a Base 36 numbering system employing both numerals and letters. These two-number sets start with $00,01,02,03,04,05$, $06,07,08,09,0 \mathrm{~A}, 0 \mathrm{~B} \ldots \mathrm{OZ}$, followed by 10-1Z, 20-2Z, etc.

The CID number appears on each page of the manuscript. The complete citation is used on the first page, and an abbreviated version on subsequent pages. Numbers in the index correspond to the last two digits of the six-digit CID number. 


\section{Contents}

ix Conference Committee

xi Symposium Committees

\section{SESSION 1 ADVANCED MATERIALS AND APPLICATIONS}

682902 Photorefractive effect of ferroelectric liquid crystals with an applied alternating electric field [6829-19]

T. Sasaki, N. Moriya, Y. Iwasaki, Tokyo Univ. of Science (Japan)

682907 Research on channel character of solar blind UV communication [6829-82]

Y. Tang, G. Ni, Z. WU, L. Zhang, Y. Lin, Beijing Institute of Technology (China)

\section{SESSION 2 LASER INTERFEROMETRY AND OPTICAL PROFILOMETRY}

682908 Sinusoidal wavelength-scanning interferometers for shape measurements (Invited Paper) [6829-56]

O. Sasaki, Niigata Univ. (Japan)

682909 Depth scanning with wavelength-stepped laser-diode interferometer [6829-84]

R. Onodera, Univ. of Industrial Technology (Japan); Y. Ishii, Tokyo Univ. of Science (Japan)

6829 0A Phase-shifting laser diode Sagnac interferometer for surface profile measurement [6829-33]

T. Suzuki, M. Shirai, O. Sasaki, Niigata Univ. (Japan)

6829 OC Multi-period fringe projection interferometry using back-propagation method for shape measurement of glass plate [6829-91]

H. Huan, O. Sasaki, T. Suzuki, Niigata Univ. (Japan)

\section{SESSION 3 OPTICAL METROLOGY, SENSING, AND IMAGING}

$6829 \mathrm{OE}$ Influence of angle misalignment on detection polarization coupling in white light interferometer [6829-34]

H. Zhang, T. XU, W. Jing, D. Jia, T. Feng, K. Liu, Y. Zhang, Tianjin Univ. (China)

6829 OF UV-VUV spectral irradiance responsivity space calibration for remote sensing spectroradiometer [6829-48]

H. Yu, S. Wang, G. Lin, L. Wang, Changchun Institute of Optics, Fine Mechanics and Physics (China)

\section{SESSION 4 OPTICAL METROLOGY AND RANGE MEASUREMENT}

6829 0l Study on key techniques for synthetic aperture ladar system [6829-01]

C. Cao, X. Zeng, Z. Feng, W. Zhang, L. Su, Xidian Univ. (China) 
6829 0J Precision circular target location in vision coordinate measurement system [6829-35]

L. Wang, L. Zhang, Z. YU, F. Chen, X. Si, D. He, Civil Aviation Univ. of China (China)

6829 OK Application of improved cubic convolution interpolation in circular target location [6829-37]

Z. YU, Civil Aviation Univ. of China (China); X. Si, Northeast Dianli Univ. (China); Y. XU, D. He,

L. Xia, Q. Gao, Civil Aviation Univ. of China (China)

SESSION 5 MATERIALS AND DEVICES FOR OPTICAL METROLOGY

6829 OM Online measuring method for PCB film using linear CCD [6829-44]

T. Ye, K. WU, F. Zhuang, Hangzhou Dianzi Univ. (China)

682900 Research on structural properties of $\mathrm{ZnO}$ thin films deposited on different substrates [6829-79]

X. Chen, Y. Xue, C. YU, J.-P. Zhang, C. Fu, X. Chen, H. Li, Tianjin Univ. of Technology (China)

\section{SESSION 6 MEASUREMENT SYSTEMS FOR SENSING DEVICES}

6829 OR Frequency stabilization of a semiconductor laser using both Rb saturated absorption profiles and double optical feedback systems [6829-30]

K. Nakano, S. Maehara, M. Yanagisawa, K. Doi, T. Sato, M. Ohkawa, T. Maruyama, Niigata Univ. (Japan); S. Kawamura, National Astronomical Observatory (Japan)

6829 OS Effect of misalignment on rotating coupling efficiency of the Dove prism [6829-38]

D. Jia, C. YU, W. Jing, H. Zhang, Y. Zhang, Tianjin Univ. (China)

\section{SESSION 7 MATERIALS AND DEVICES FOR FIBER SENSORS I}

6829 OU Scanned Talbot interferometer based on fiber translation for changing written Bragg wavelength [6829-04]

C. Li, Kunming Univ. of Science and Technology (China); Y. M. Zhang, T. G. Liu, J. F. Jiang, Tianjin Univ. (China); Z. Wan, M. J. Li, Y. Wang, Kunming Univ. of Science and Technology (China)

6829 0X Influence of birefringence dispersion on spatial resolution of a distributed stress sensor using birefringence optical fiber [6829-45]

T. Xu, W. Jing, H. Zhang, C. Huang, K. Liu, D. Jia, Y. Zhang, Tianjin Univ. (China)

\section{SESSION 8 MATERIALS AND DEVICES FOR FIBER SENSORS II}

$6829 \mathrm{OZ}$ Study of the fiber's photosensitivity with Boron doped in the fiber's core [6829-77]

F. Tu, D. Liu, Huazhong Univ. of Science and Technology (China); J. Luo, Yangtze Optical and Cable Co., Ltd. (China)

682910 A new fiber Fabry-Perot cavity sensor [6829-85]

Y. Gao, Z. Zhang, Z. Zhao, Y. Luo, M. Zhou, T. Ding, Jinan Univ. (China) 
682911 Improvement of miniature grating spectrometers [6829-53]

H. Yang, L. XU, K. Chen, X. Huang, Q. He, G. Jin, Tsinghua Univ. (China)

682912 Research of anti-blooming array CCD image sensor [6829-14]

J. Wang, Y. Gao, Y. Yang, H. Zeng, T. Xie, Xi'an Univ. of Technology (China)

682913 Improved measurement methods for motion picture resolution of LCD [6829-24]

F. Liu, Beijing Institute of Technology (China); X. G. Liang, Zhejiang Univ. (China); Y. J. Zhao, Beijing Institute of Technology (China); L. C. Wang, Institute of Process Engineering (China); F. Yu, Beijing Institute of Technology (China)

682915 A CdSe quantum dot photodetector for hyperspectral imaging in the visible region [6829-69]

T. Jiang, A. Dindar, J. Therrien, Univ. of Massachusetts, Lowell (USA)

\section{POSTER SESSION}

682916 Fiber-based SPR sensors with calibration function [6829-02]

Z. Zhang, F. Sun, G. Xiao, National Research Council (Canada); Y. Wu, Shanghai Institute of Microsystem and Information Technology (China)

682919 Novel viewpoint for explaining thermal degradation mechanism of fiber Bragg gratings [6829-08]

W. Wang, W. Wu, Guangdong Ocean Univ. (China); J. Lin, Dalian Univ. of Technology

(China)

6829 1A Signal processing methods in a single-photon counting system [6829-09]

Y. Chen, M. Du, R. Li, Fuzhou Univ. (China)

6829 1B A method for measuring modulation transfer function of CCD device in remote camera with grating pattern [6829-12]

Y. Chen, X. Chen, W. Shen, Soochow Univ. (China)

6829 1C Study on microstructure of amorphous GaAs and hydrogen doped amorphous GaAs thin films [6829-13]

Y. Yao, C. Liu, Changchun Univ. of Science and Technology (China) and Jilin Normal Univ. (China); B. Bo, Changchun Univ. of Science and Technology (China)

6829 1D Experimental research on dimensional measurement of hot parts based on CCD [6829-15] J. Wang, Tianjin Univ. (China) and Tianjin Univ. of Technology (China); Z. Qiu, J. Li, Tianjin Univ. (China)

6829 1E A new camera calibration method for phase measuring profilometry [6829-18]

D. Wu, Beijing Univ. of Posts and Telecommunications (China) and Beijing Information Science \& Technology Univ. (China); N. Lu, Beijing Information Science \& Technology Univ. (China) 
$6829 \mathrm{lF}$ Investigations of fluorescence resonance energy transfer between CdTe quantum dot donors and gold nanoparticle quenchers in DNA sensing [6829-25]

S. XU, J. Zhang, Q. Dong, Tianjin Polytechnic Univ. (China); B. Sun, Nankai Univ. (China)

6829 1G Design of quantum efficiency measurement system for variable doping GaAs photocathode [6829-27]

L. Chen, China Jiliang Univ. (China) and Nanjing Univ. of Science and Technology (China);

K. Yang, H. Liu, China Jiliang Univ. (China); B. Chang, Nanjing Univ. of Science and Technology (China)

$6829 \mathrm{1H}$ Analytical discussion of semiconductor lasers for gravitational-wave detection [6829-28] T. Uehara, A. Sato, T. Sato, M. Ohkawa, T. Maruyama, Niigata Univ. (Japan); S. Kawamura, National Astronomical Observatory (Japan)

6829 1I Camera calibration method used in computer vision coordinate measurement systems [6829-32]

Z. YU, X. Li, W. Tian, M. Gong, D. He, L. Xia, Civil Aviation Univ. of China (China)

$6829 \mathrm{lL}$ Study on a novel optical readout ferroelectric device based on MIS for uncooled infrared imaging [6829-41]

J. H. Qin, J. H. Ma, Z. M. Huang, J. H. Chu, Shanghai Institute of Technical Physics (China)

6829 1M 3D space positioning and image feature extraction for workpiece [6829-49]

B. Ye, Y. Hu, Hefei Univ. of Technology (China)

6829 iN Dynamic displacement measurement of Low-E membrane reactor by PSD based on lasertriangulation method [6829-50]

B. Li, T. Liu, Y. Zhang, Tianjin Univ. (China)

682910 Output characteristics of Q-switched fiber laser based on electro-optic ceramics [6829-52] W. Guo, Nankai Univ. (China); E. Li, Tianjin Univ. (China); C. Tu, Y. Li, S. Zhang, F. Lu, Nankai Univ. (China)

$6829 \mathrm{lP}$ Target recognition in a turbid medium with backscattered polarization patterns [6829-54] L. Xu, Fujian Normal Univ. (China); X. Xu, Fuzhou Univ. (China); Y. Zheng, Fujian Normal Univ. (China); W. Su, Fuzhou Univ. (China); J. Lin, Fujian Normal Univ. (China)

6829 1Q A wavelength calibration process for micro-spectrometers with multichannel detectors [6829-55]

X. Huang, H. Yang, Q. He, G. Jin, Tsinghua Univ. (China)

6829 IR Hydrogen sensors based on Pt-AIGaN/AIN/GaN Schottky diode [6829-57]

$X$. Wang, Institute of Semiconductors (China); X. Wang, Institute of Semiconductors (China) and Key Lab. of Semiconductor Materials Science (China); H. Xiao, C. Feng, B. Wang,

C. Yang, J. Wang, C. Wang, J. Ran, G. Hu, J. Li, Institute of Semiconductors (China)

6829 is Effect of pixel active area shape on imaging quality of CMOS active pixel sensor [6829-58] H. Fan, W. XU, Donghua Univ. (China); C. Wang, Shanghai Institute of Technical Physics (China) 
6829 1T The design of a laser-based digital displacement/deflection measurement system of a remote object and its calibration [6829-59]

C. Tang, E. Li, Tianjin Univ. (China)

$68291 \mathrm{U}$ Design and signal processing of a sector SSPA for PM2.5 monitoring [6829-61]

K. Wu, L. Ma, M. Guo, P. Jiang, Hangzhou Dianzi Univ. (China)

6829 IV Signal processing method of the diameter measurement system based on CCD parallel light projection method [6829-63]

Q. Song, S. Zhu, H. Yan, W. Wu, Beijing Univ. of Posts and Telecommunications (China)

6829 IW Study on the operating range in solar blind ultraviolet detecting system [6829-64]

C. Yang, Q. Zeng, Univ. of Electronic Science and Technology of China (China) and Southwest Institute of Technical Physics (China); D. Zhu, Univ. of Electronic Science and Technology of China (China); C. Gan, Southwest Institute of Technical Physics (China)

6829 1X Novel liquid photoacoustic cells with inner multi-beam photoacoustic source [6829-66] J. Yang, Y. Zhao, Northeastern Univ. (China) and Tsinghua Univ. (China); S.-Y. Yang, Tsinghua Univ. (China)

6829 IY A fiber grating dual-parameter sensor of ditrigon cantilever beam for measurement of strain and temperature [6829-72]

J. Zhang, Beijing Univ. of Posts and Telecommunications (China) and Henan Univ. (China);

C. Yu, K. Wang, C. Li, J. Zeng, Beijing Univ. of Posts and Telecommunications (China)

$68291 Z$ Development of new optical fiber tolvene sensor [6829-73]

Y. Fujii, S. Honma, M. Morisawa, S. Muto, Univ. of Yamanashi (Japan)

682920 Development of polymer optical waveguide-type alcohol sensor [6829-74]

J. Nagata, S. Honma, M. Morisawa, S. Muto, Univ. of Yamanashi (Japan)

682921 Plastic optical fiber sensor system for detecting multi-point gas leakages [6829-75]

H. Suzumori, S. Honma, M. Morisawa, S. Muto, Univ. of Yamanashi (Japan)

682922 Improvement of plastic optical fiber microphone based on moisture pattern sensing in devoiced breath [6829-76]

T. Taki, S. Honma, M. Morisawa, S. Muto, Univ. of Yamanashi (Japan)

682925 Ultra-accuracy parallel electronic datum optical metrology system of systems [6829-89]

X.-W. Xiong, W. L. Bear, Wynn Bear International Cutting-Edge High-Tech Institute (China);

J. T. Roth, Pennsylvania State Univ., Erie (USA); M. P. Schoen, Idaho State Univ. (USA)

682927 Interferometric sensing for measuring the complex amplitudes of a 3-D object by R, G and B tunable lasers [6829-92]

J. Sato, Y. Ishii, Tokyo Univ. of Science (Japan)

682928 Multiple phase-shifting white-light interferometry for quantitative detection [6829-93]

T. Terasawa, A. Wada, Y. Ishii, Tokyo Univ. of Science (Japan)

Author Index 
Downloaded From: https://www.spiedigitallibrary.org/conference-proceedings-of-spie on 26 Apr 2023

Terms of Use: https://www.spiedigitallibrary.org/terms-of-use 


\title{
Conference Committee
}

\author{
Conference Chairs
}

Anbo Wang, Virginia Polytechnic Institute and State University (USA)

Yimo Zhang, Tianjin University (China)

Yukihiro Ishii, Tokyo University of Science (Japan)

Program Committee

Jun Chen, Tokyo Polytechnic University (Japan)

Xiangang Luo, Chengdu Opto-Electric Institute (China)

Kazuhiko Oka, Hokkaido University (Japan)

Ribun Onodera, University of Industrial Technology (Japan)

Yukitoshi Otani, Tokyo University of Agriculture and Technology (Japan)

Gang-Ding Peng, University of New South Wales (Australia)

Yunjiang Rao, Chengdu University of Electronic Science and Technology (China)

Osami Sasaki, Niigata University (Japan)

Tsutomu Shimura, The University of Tokyo (Japan)

Hongbo Sun, Jilin University (Japan)

Mitsuo Takeda, University of Electro-Communications (Japan)

Yaolin Wang, Shanghai Institute of Micro-Systems (China)

Hai Xiao, University of Missouri, Rolla (USA)

Miao Yu, University of Maryland (USA)

\section{Session Chairs}

1 Advanced Materials and Applications

Hongbo Sun, Jilin University (Japan)

2 Laser Interferometry and Optical Profilometry

Jun Chen, Tokyo Polytechnic University (Japan)

3 Optical Metrology, Sensing, and Imaging

Ribun Onodera, University of Industrial Technology (Japan)

$4 \quad$ Optical Metrology and Range Measurement

Yunjiang Rao, Chengdu University of Electronic Science and Technology (China) 
5 Materials and Devices for Optical Metrology

Yukitoshi Otani, Tokyo University of Agriculture and Technology (Japan)

6 Measurement Systems for Sensing Devices

Xiangang Luo, Chengdu Opto-Electric Institute (China)

7 Materials and Devices for Fiber Sensors I

Takamasa Suzuki, Niigata University (Japan)

8 Materials and Devices for Fiber Sensors II

Yaolin Wang, Shanghai Institute of Micro-Systems (China)

9 CCD and C-MOS Technologies

Kazuhiko Oka, Hokkaido University (Japan) 


\title{
Symposium Committees
}

\author{
General Chairs \\ Brian Culshaw, University of Strathclyde (United Kingdom) \\ Bingkun Zhou, Tsinghua University (China) and COS-Chinese Optical \\ Society (China) \\ General Cochairs
}

Arthur Chiou, National Yang-Ming University (Taiwan, China)

Mitsuo Takeda, University of Electro-Communications (Japan)

Chungli Bai, Chinese Academy of Sciences (China)

Seung-Han Park, Yonsei University (South Korea)

Zhizhan Xu, Shanghai Institute of Optics and Fine Mechanics

(China)

Jianlin Cao, China Ministry of Science and Technology (China)

Junhao Chu, Shanghai Institute of Technical Physics (China)

Jingming Kuang, Beijing Institute of Technology (China)

Xiaomin Ren, Beijing University of Posts and Telecommunications (China)

Dingbo Kuang, Shanghai Institute of Technical Physics (China)

Guozheng Yang, Institute of Physics (China)

Honorary Chairs

Daheng Wang, Chinese Academy of Sciences (China)

Guoguang Mu, Nankai University (China)

Technical Program Chair

Songlin Zhuang, Shanghai University of Science and Technology (China)

Technical Program Cochairs

Xun Hou, Xian Institute of Optics and Precision Mechanics (China)

Qian Mao, Wuhan Research Institute of Posts and Telecommunications (China)

Xu Liu, Zhejiang University (China)

Local Organizing Committee Chair

Shusen Xie, Fujian Normal University (China)

Local Organizing Committee Cochairs

Guoqiang Ni, Beijing Institute of Technology (China)

Qihuang Gong, Peking University (China)

Ying Gu, PLA General Hospital (China)

Huilin Jiang, Changchun University of Science and Technology (China) 
General Secretary

Guoqiang Ni, Beijing Institute of Technology (China)

Administrative Vice General Secretary

Boyu Ding, Beijing Institute of Technology (China)

Vice General Secretaries

Hanyi Zhang, Tsinghua University (China)

Ya Cheng, Shanghai Institute of Optics and Fine Mechanics (China)

Zhongwei Fan, Academy of Opto-electronics (China)

Jianxin Chen, Fujian Normal University (China)

Lan Wu, Zhejiang University (China)

Shaowen Wang, COS-Chinese Optical Society (China)

Yuejin Zhao, Beijing Institute of Technology (China)

Chongxiu Yu, Beijing University of Posts and Telecommunication (China)

Jun Ruan, China Solid State Lighting Research and Industry Alliance

(China)

Local Organizing Committee Members

Kangnan Qi, Beijing Optical Society (China)

Chunqing Gao, Beijing Institute of Technology (China)

Tiegen Liu, Tianjin University (China)

Lanxing Shao, Shanghai Optical Society (China)

Zaixuan Zhang, Chinese Jiliang University (China)

Hongda Chen, Institute of Semiconductors (China)

Baosheng Liu, Beijing Optical Society (China)

Xin Wang, Hubei Optical Society (China)

Lin Zhai, COS-Chinese Optical Society (China)

Zhiqiang Zhu, East China Normal University (China)

Lei Xu, Fudan University (China)

Hezhou Wang, Zhongshan University (China)

Zhiming Yi, Ofstar Tech Company, Ltd., Shenzhen (China) 